\title{
Yeni Tanı Alan Nadir Faktör Eksikliği Olan Hastalarımız: 5 Yıllık Deneyim
}

\author{
Newly Diagnosis Patients With A Rare Factor Deficiency: Five Years Experience

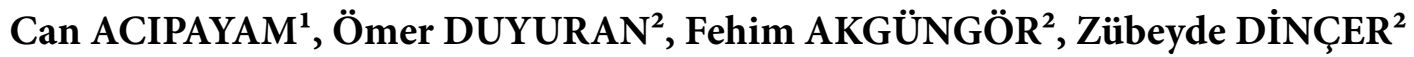 \\ ${ }^{1}$ Doç.Dr. Kahramanmaraş Sütçü İmam Üniversitesi Tip Fakültesi, Çocuk Hematoloji ve Onkoloji Bilim Dalı, KAHRAMANMARAŞ \\ ${ }^{2}$ Arş.Gör.Dr. Kahramanmaraş Sütçü İmam Üniversitesi Tıp Fakültesi, Çocuk Sağlığı ve Hastalıkları Anabilim Dalı, KAHRAMANMARAŞ
}

\section{Öz}

Amaç: Kanama bozuklukları arasında fibrinojen (Faktör I), Faktör II, Faktör V, kombine Faktör V ve Faktör VIII, Faktör VII, Faktör X, Faktör XI, Faktör XII ve Faktör XIII eksiklikleri, dünya genelinde nadir görülür. Tüm faktör eksikliklerinin \%3-5'ini oluşturur. Nadir faktör eksikliği olan hastalarda heterojen klinik tablo görülür. Hafif ya da orta dereceli kanamadan ciddi ve hayatı tehdit eden kanamalara kadar farklı semptomlar görülebilir. Bu çalışmada hastanemizde yeni tanı alan nadir faktör eksikliği olan hastaların değerlendirilmesi amaçlandi.

Gereç ve Yöntemler: Ocak 2014 ve Ocak 2019 yılları arasında Kahramanmaraş Sütçü İmam Üniversitesi Tip Fakültesi Çocuk Hematoloji ve Onkoloji Bölümü’nde tanı alan nadir faktör eksikliği olan 18 yaş altı hastalar incelendi.

Bulgular: Nadir faktör eksikliği olan 17 hastanın 9'u $(\% 52,9)$ erkek, 8'i $(\% 47,1)$ kızdı. Hastaların ortalama tanı yaşı 7,6 $\pm 4,3$ yıl (0-14 yıl) güncel yaşı $9,5 \pm 4,6$ yıl (1-16 yll) ve faktör düzeyi $\% 9,1 \pm 11,1$ olarak bulundu. Hastaların 8'inde Faktör VII, 3'ünde Faktör XIII, 2'sinde Faktör V, 2'sinde Faktör XII, 1'inde Faktör V ve VIII ve l'inde Faktör I eksikliği tanısı konuldu. On yedi hastanın 9'unda kanama vardı. İkisi diş eti, 2'si burun, 1'i göbek, 1'i iliopsoas, 1'i gastrointestinal sistem, 1'i sünnet sonrası kanama ve l'i topuk kanı alınırken kanamanın durmaması şeklindeydi. Ciddi kanama olan 5 hastanın 3'ü Faktör XIII, 1'i Faktör VII ve 1'i Faktör I eksikliği tanılıydı. Faktör I eksikliği olan kız hasta 10 günlükken topuk kanı alımı sırasında kanamanın durmaması nedeniyle tanı aldı. En küçük yaşta tanı konulan kız hasta 6 günlükken ciddi göbek kanaması nedeniyle hastanemize başvurdu ve Faktör XIII eksikliği tanısı konuldu. Faktör XIII eksikliği tanısı olan bir kız hasta bisikletten düşme nedeniyle oluşan iliopsoas kanaması ve sonrasında gelişen intrakranial kanama nedeniyle 8 yaşında eksitus oldu.

Sonuç: Kanama şikâyeti olan ya da olmayan hastalarda nadir faktör eksikliği tanısı ayırıcı tanıda olmalıdır. Bu hastaların erken dönemde tanısı konularak, ciddi kanamaların önlenmesi ve tedavisi önemlidir.

Anahtar Kelimeler: Nadir faktör eksiklikleri, kanama, çocuk

\section{GÍRIŞ}

Kanama bozuklukları arasında fibrinojen (Faktör I), Faktör II, Faktör V, kombine Faktör V ve Faktör VIII, Faktör VII, Faktör X, Faktör XI, Faktör XII ve Faktör XIII eksiklikleri, dünya genelinde nadir görülür. Tüm

$\begin{array}{ll}\text { İletişim: } & \begin{array}{l}\text { Doç. Dr. Can ACIPAYAM, KSÜ Tip Fakültesi, Çocuk } \\ \text { Sağlığı ve Hastalıkları AD, Kahramanmaraş }\end{array} \\ \text { DOI: } & \mathbf{1 0 . 1 7 5 1 7 / k s u t f d . 5 4 0 5 0 3}\end{array}$

\section{Abstract}

Objective: Hemorrhagic disorders include fibrinogen (Factor I), Factor II, Factor V, combined Factor V, and Factor VIII, Factor VII, Factor X, Factor XI, Factor XII, and Factor XIII deficiencies. It constitutes $3-5 \%$ of all factor deficiencies. A heterogeneous clinical picture is seen in patients with rare factor deficiency. From mild to moderate bleeding to severe and life-threatening bleeding, different symptoms may occur. The aim of this study was to evaluate the patients with newly diagnosed rare factors in our hospital.

Material and Methods: Patients under 18 years of age with a rare factor deficiency diagnosed in the Department of Pediatric Hematology and Oncology, Faculty of Medicine, Kahramanmaraş Sütçü İmam University between January 2014 and January 2019 were examined.

Results: Of the 17 patients with rare factor deficiency, 9 $(52.9 \%)$ were male and $8(47.1 \%)$ were female. The mean age at diagnosis was $7.6 \pm 4.3$ years ( 0 - 14 years), the mean age was $9.5 \pm 4.6$ years (1-16 years) and factor level 9,1 $\pm 11,1 \%$. Factor VII was diagnosed in 8 patients, Vactor XIII in 3 patients, Vactor V in 2 patients, Factor XII in 2 patients, Factor V and VIII in 1 patient and factor I deficiency in 1 patient. 9 out of 17 patients had bleeding. Two had gums, 2 had nose, 1 had umbilical cord, 1 had iliopsoas, 1 had gastrointestinal system, 1 had hemorrhage after circumcision and 1 had heel blood while bleeding did not stop. Of the 5 patients with severe bleeding, 3 had Factor XIII, 1 had Factor VII and 1 had Factor I deficiency. The girl patient with Factor I deficiency was diagnosed at the age of 10 days because he did not stop bleeding during heel blood intake. The girl patient, who was diagnosed at the young age, was admitted to our hospital with severe belly bleeding at the age of 6 days and was diagnosed as Factor XIII deficiency. A girl patient with Factor XIII deficiency died at the age of 8 due to iliopsoas hemorrhage due to falling off the bicycle and after occurring intracranial hemorrhage.

Conclucion: The diagnosis of rare factor deficiency should be in the differential diagnosis in patients with or without bleeding complaints. Early diagnosis of these patients is important and prevention and treatment of serious bleeding are important.

Key Words: Rare factor deficiencies, hemorrhage, child

faktör eksikliklerinin \%3-5'ini oluşturur. Nadir faktör eksikliklerinin kalıtım tipi genellikle otozomal resesiftir (1). Bu nedenle erkeklerin yanı sıra kızlarda da görülebilir. Nadir faktör eksikliği olan hastalarda heterojen klinik tablo görülür. Hafif ya da orta dereceli kanamadan ciddi

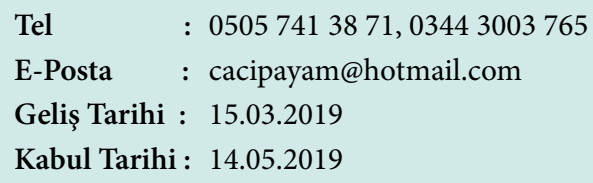


ve hayatı tehdit eden kanamalara kadar farklı semptomlar görülebilir. Nadir faktör eksikliklerinde görülen en tipik semptomlar mukozal sistem ve invaziv işlemler sırasında oluşan beklenmedik kanamalardır. En ciddi semptomlar intrakranial kanamalarda oluşur (Faktör VII ve Faktör XIII eksikliğinde daha sık görülür). Gastrointesitnal sistem kanamaları, tekrarlayan hematomlar ve hemartrozlar Faktör X eksikliğinde daha sık görülür (2). Tekrarlayan ciddi kanaması olan kişilerde profilaksi düşünülebilir.

Dünya Hemofili Federasyonu'na göre, nadir faktör eksikliklerinden Faktör XI ve Faktör VII eksikliği daha sık görülür ve toplam nadir faktör eksikliklerinin (sırasıyla) \%37 ve \%23'ünü oluşturur. Fibrinojen ve Faktör V eksiklikleri \%10'unu, Faktör X eksikliği \%9 ve Faktör XIII eksikliği \%6'sını oluşturur. Kombine Faktör V ve Faktör VIII (\%3) ve Faktör II (\%2) eksiklikleri en nadir kanama bozuklukları olarak rapor edilmiştir (3). Kalıtsal nadir faktör eksikliklerinin tanısı doğum öncesi amniyosentez ve koryonik villus örneklemesi ile konulabilmektedir. Bilinen mutasyonlar araştırılabilir. Prenatal erken tanı hamileliğin devamı hakkında karar alma ve erken müdahale için avantaj sağlar (3).

$\mathrm{Bu}$ çalışmada 5 yıllık süreçte yeni tanı alan nadir faktör eksikliği olan hastaların bilgileri paylaşılması amaçlanmıştır.

\section{GEREÇ VE YÖNTEM}

Bu çalışmada nadir faktör eksikliği tanısı konulan hastaların laboratuar değerleri, kanama durumları ve ciddiyetlerinin belirlenmesi amaçlandı. Ocak 2014 ve Ocak 2019 yılları arasında Kahramanmaraş Sütçü İmam Üniversitesi Tip Fakültesi Çocuk Hematoloji ve Onkoloji Bölümü’nde tanı alan nadir faktör eksikliği olan 18 yaş altı hastalar retrospektif olarak değerlendirildi. Hastalara ait bilgiler hasta dosyalarından alındı. Hastaların yaş, cinsiyet, tanı yaşı, faktör düzeyleri, beyaz küre, hemoglobin, hematokrit, ortalama eritrosit hacmi, platelet sonuçları, kanama sıklıkları, kanama ciddiyetleri ve kanama yerleri incelendi. Elde edilen veriler "IBM SPSS Statistics 22" istatiksel paket programı kullanılarak ortalama, standart sapma, frekans ve yüzde dağılımlar elde edildi.

\section{BULGULAR}

Nadir faktör eksikliği olan 17 hastanın 9'u (\% $52,9)$ erkek, 8’i $(\% 47,1)$ kızdı. Hastaların ortalama tanı yaşı $7,6 \pm 4,3$ yıl (0-14 yil), güncel yaşı $9,5 \pm 4,6$ y1l (1-16 yıl), beyaz küre sayıs $9185 \pm 3392 / \mathrm{mm} 3$, hemoglobin $13,1 \pm 2,1 \mathrm{~g} / \mathrm{dL}$, hematokrit $\% 38,6 \pm 5,4$, ortalama eritrosit hacmi $80,4 \pm 6,8 \mathrm{fL}$, trombosit sayıs $327437 \pm 114316 / \mathrm{mm} 3$ ve faktör düzeyi $\% 9,1 \pm 11,1$ olarak bulundu. Hastaların 8 'inde Faktör VII, 3'ünde Faktör XIII, 2'sinde Faktör V, 2'sinde Faktör XII, 1'inde Faktör V ve VIII ve 1'inde Faktör I eksikliği tanısı konuldu (Tablo 1).

On yedi hastanın 9'unda kanama vardı. İkisi diş eti, 2'si burun, 1'i göbek, 1'i iliopsoas, 1'i gastrointestinal sistem, 1'i sünnet sonrası kanama ve 1'i topuk kanı alınırken kanamanın durmaması şeklindeydi. Ciddi kanama olan 5 hastanın 3'ü Faktör XIII, 1'i Faktör VII ve l'i Faktör I eksikliği tanılıydı. Faktör I eksikliği olan hasta
10 günlükken topuk kanı alımı sırasında kanamanın durmaması nedeniyle tanı aldı. En küçük yaşta tanı konulan kız hasta 6 günlükken ciddi göbek kanaması nedeniyle hastanemize başvurdu ve Faktör XIII eksikliği tanısı konuldu. Faktör XIII eksikliği tanısı olan bir kız hasta bisikletten düşme nedeniyle oluşan iliopsoas kanaması ve sonrasında gelişen intrakranial kanama nedeniyle 8 yaşında exitus oldu.

Faktör VII eksikliği olan 8 hastanın 1'i kız, 7'si erkekti. Faktör VII eksikliği olan hastaların ortalama tanı yaşı $8,6 \pm 4,5$ yıl ( 2 ay-14 yıl), güncel yaşı $10,6 \pm 4,0$ yıl (516 yll), beyaz küre sayıs1 $8901 \pm 3098 / \mathrm{mm} 3$, hemoglobin $13,7 \pm 1,1 \mathrm{~g} / \mathrm{dL}$, hematokrit $\% 39,9 \pm 3,1$, ortalama eritrosit hacmi $82,8 \pm 8,3 \mathrm{fL}$ ve trombosit sayis1 $284625 \pm 67341 /$ mm3 olarak bulundu (Tablo 1). Faktör VII eksikliği olan 5 hastada kanama yoktu. Kanama olan 3 hastanın ikisinde ciddi olmayan burun kanaması vardı. Ciddi kanaması olan erkek hasta 2 aylikken tanı aldı ve tekrarlayan ciddi gastrointestinal kanamaları (kanama durumunda rekombinant aktive faktör VIIa (rFVIIa) tedavisi alıyor) vardı. Bu hastanın erkek kardeşi de aile taramasıyla 7 yaşında faktör VII eksikliği tanısı aldı ve kanama şikâyeti yoktu.

\section{TARTIŞMA}

Afibrinojeneminin (Faktör I) tahmini prevalansı milyonda birdir. Kadınlarda daha sık görülür. Otozomal resesif geçişlidir. Prevalanstaki coğrafi farklılıklar akraba evliliklerine bağlıdır. Fibrinojen, karaciğerde sentezlenir, fibrin pihtısı oluşumuna katılır, primer substrattır. Olguların \%85'i yenidoğan döneminde göbek kanaması ile kendini gösterir. Mukoza kanaması, hematomlar en sık rastlanan kanama bulgularındandir (4). Bizim çalışmamızda hastalarımızın birinde Faktör I eksikliği mevcuttu. On günlükken topuk kanı alımı sonrası kanamanın durmaması nedeniyle başvurdu ve afibrinojenemi tanısı konuldu.

Genel olarak Faktör V eksikliğinin prevalansı konusunda yeterli veri olmasa da milyonda bir olduğu düşünülmektedir. Faktör V, yapı olarak Faktör VIII ile benzerlik göstermektedir. Kanamalar genelde deri ve mukoza kanamaları şeklindedir ve doğumu takip eden ilk yıllar içerisinde görülür. Ancak daha geç yaşlarda tanı alan hastalar da mevcuttur (4). Bizim çalışmamızda hastaların 2'sinde Faktör V eksikliği mevcuttu. Hastaların biri erkek biri kızdı ve hastalar sırasıyla 8 yaş ve 9 yaşında tanı aldılar. Ciddi kanamaları olmadı. Hastalar tedavi ya da profilaksi almadılar. Bir hastamızada kombine Faktör V ve Faktör VIII eksikliği tanısı konuldu. Hastamız 12 yaşındaydı ve ciddi kanaması yoktu.

Faktör VII, 13. kromozomun uzun kolunda (13q34) bulunan gen tarafından kodlanır. Karaciğerde $\mathrm{K}$ vitamini ile sentezlenen, pihtılaşma mekanizmasında ekstrensek yolda yer alan bir proteindir. Yarılanma ömrü kısadır (3-6 saat) (5). Homozigot ya da heterozigot olgularda Faktör VII'nin tamamen yokluğu söz konusu değildir. Heterozigot bireyler tamamen sağliklı olup travma sonrasında bile kanama gözlenmeyebilir. Homozigot bireyler semptomatik olup hafif burun kanamalarından, ağır kafa içi kanamalarına kadar çok farklı şiddette kanama tabloları gösterebilir. Hayatı tehdit eden kafa içi ve gastrointestinal sistem kanamaları özellikle yenidoğan 
Tablo 1. Hastaların demografik ve laboratuvar özellikleri.

\begin{tabular}{|c|c|c|c|c|c|c|c|c|c|c|c|c|}
\hline & ${ }^{\star} F I$ eks. & $\begin{array}{l}F V \\
e k s .\end{array}$ & $\begin{array}{l}{ }^{\star} F V+- \\
V I I I \text { eks. }\end{array}$ & $\begin{array}{l}\text { FVII } \\
\text { eks. }\end{array}$ & $\begin{array}{l}{ }^{*} F X I I \\
e k s .\end{array}$ & $\begin{array}{l}\text { FXIII } \\
\text { eks. }\end{array}$ & Toplam & & & & & \\
\hline & $K$ & $K$ & $E$ & $K$ & K & $E$ & $K$ & $K$ & $E$ & $K$ & $E$ & $T$ \\
\hline $\operatorname{Sayi}(n)$ & 1 & 1 & 1 & 1 & 1 & 7 & 2 & 2 & 1 & 8 & 9 & 17 \\
\hline $\begin{array}{l}\text { Tanı Yaşı(yıl) } \\
\text { Ortalama }\end{array}$ & 0 & 8 & 9 & 12 & 8 & 8,7 & 8 & 4 & 1 & 6,5 & 7,9 & 7,6 \\
\hline $\begin{array}{l}\text { Yaş(yıl) } \\
\text { Ortalama }\end{array}$ & 1 & 8 & 12 & 16 & 9 & 10,8 & 10 & 4,5 & 6 & 7,9 & 10,4 & 9,5 \\
\hline $\begin{array}{l}\text { WBC }(/ \mathrm{mm} 3) \\
\text { Ortama }\end{array}$ & 15520 & 9820 & 7000 & 17710 & 7810 & 9057 & 7100 & 9765 & 7360 & 10573 & 8640 & 9185 \\
\hline $\begin{array}{l}H G B(g / d L) \\
\text { Ortalama }\end{array}$ & 17,8 & 12,8 & 13,5 & 9,6 & 13,2 & 13,8 & 12,4 & 11,8 & 10,3 & 12,7 & 13,4 & 13,1 \\
\hline $\begin{array}{l}\text { HCT }(\%) \\
\text { Ortalama } \\
\end{array}$ & 51,7 & 39,8 & 38,2 & 28,9 & 38,3 & 40,1 & 37,6 & 34,5 & 33,5 & 37,9 & 39,2 & 38,6 \\
\hline $\begin{array}{l}M C V(f L) \\
\text { ortalama }\end{array}$ & 100 & 77,6 & 81,1 & 75,9 & 80,7 & 83,1 & 80 & 80,1 & 72,1 & 81,8 & 81,6 & 80,5 \\
\hline $\begin{array}{l}P L T(x 103 / \mathrm{mm} 3) \\
\text { Ortalama }\end{array}$ & 77 & 343 & 374 & 343 & 397 & 268 & 370 & 411 & 549 & 340 & 311 & 327 \\
\hline $\begin{array}{l}\text { Ortalama Faktör } \\
\text { Düzeyi(\%) } \\
\text { (min-maks) }\end{array}$ & 0 & 8,4 & 0,5 & 6 & 1,9 & $\begin{array}{l}18,3 \\
(2,2-37)\end{array}$ & $\begin{array}{l}4,0 \\
(3-5)\end{array}$ & $\begin{array}{l}3,5 \\
(3-4)\end{array}$ & 4,0 & $\begin{array}{l}3,9 \\
(0-8,4)\end{array}$ & $\begin{array}{l}14,3 \\
(0,5-37)\end{array}$ & $\begin{array}{l}9,1 \\
(0-37)\end{array}$ \\
\hline
\end{tabular}

FI eks.: Faktör I eksiklĭ̆i, FV eks.: Faktör V eksikliği, FV+VIII eks.: Kombinefaktör V ve faktör VIII eksikliği, FVII eks.: Faktör VII eksikliği, FXII eks.: Faktör XII eksikliği, FXIII eks.: Faktör XIII eksikliği, K: Kız, E: Erkek, T: Toplam, WBC: Lökosit sayısı, HGB: Hemoglobin HCT: Hemotokrit, MCV: Ortalama eritrosit hacmi, PLT: Platelet sayısı, min: minimum, maks: maksimum

\section{${ }^{\star}$ Sadece kiz hasta vardır}

döneminde zorlu doğumlar sonrasında gelişebilmektedir (6). Aynı mutasyona sahip bireyler bile benzer klinik tabloyu göstermeyebilirler. Bu durum hastalık fenotipinin oldukça heterojen olmasına ve hangi yaşta ortaya çıkacağının öngörülememesine neden olmaktadır $(7,8)$. Fışgın ve ark. (6) 2012 yılında yaptıkları bir çalışmada nadir görülen koagulasyon bozuklukları içinde faktör VII eksikliği görülme oranı \%34 ile en sık kanama bozukluğu olarak bildirilmiştir. Faktör VII eksikliği olan hastalarda intrakraniyal kanama oranı $\% 13,2$ ve ölüm oranı $\% 3,8$ olduğu bildirilmiştir. Bizim çalışmamızda hastaların 8'inde Faktör VII eksikliği mevcuttu. Hastaların 1'i kız 7'si erkekti, tanı yaşları 2ay-14 yaş aralığında değişkenlik gösterdi. Hastaların 5'inde kanama yoktu. Kanama olan 3 hastanın 1'inde (erkek hasta) tekrarlayan ciddi gastrointestinal kanamaları (kanama durumunda rekombinant aktive Faktör VIIa (rFVIIa) tedavisi alıyor) vardı. Bu hastanın erkek kardeşi de aile taramasıyla Faktör VII eksikliği tanısı aldı. Ciddi kanaması olan erkek hasta dışındaki 7 hasta tedavi ve proflaksi almadı.

Nadir faktör eksikliklerinden Faktör XI eksikliği sık görülmektedir (3). Faktör XI eksikliği tanısı alan hastamız bulunmamaktadır. Bunun sebebi ciddi faktör eksikliği $(\leq \% 1)$ olan bireylerde bile hafif klinik sergileyebilir. Taravmaya rağmen asemptomatik olabilir (2).

İlk defa 1955 yılında John Hageman isimli bir hastada gösterilmiş olması nedeniyle Hagemen faktör de denilen faktör XII eksikliği nadir bir durumdur. FXII eksikliği genellikle klinik belirti vermeyen bir durum olması nedeni ile gerçek sıklığı hakkında fazla veri bulunmamaktadır. Sıklığının milyonda bir olduğu tahmin edilmektedir (4). Bizim çalışmamızda hastalarımızın 2'sinde faktör XII eksikliği mevcuttu. İkiside kız olan hastalar 6 yaş ve 10 yaşlarında tanı aldılar, ciddi kanamaları hiç olmadı, herhangi tedavi ya da profilaksi almadılar.

Faktör XIII eksikliği, milyonda 1-3 sıklıkta görülen nadir bir hastalıktır. Akraba evliliğinin çok görüldüğü toplumlarda daha sık görülebilmektedir (4). İlk kez 1960 yılında Duckert tarafından bildirilmiş Faktör XIII eksikliği otozomal resesif geçişlidir ve her iki cinste de görülebilen bir hastalıktır. 1990 yılına kadar 200 üzerinde faktör 
XIII eksikliği olgusu bildirilmiştir $(9,10)$. Hasta kişilerde Faktör XIII düzeyi normal değerin \%1'inden azdır. Hemen hepsinde doğum sonrası göbek kordonundan kanama görülür. Hastalık ekimoz ve hematom oluşumu, travma sonrası uzun süren kanamalarla kendini gösterir. Kanama çoğu kez travmadan hemen sonra başlar, bazen ise 12-36 saat sonrasında görülebilir. Hasta kadınlarda gebelikte tekrarlayan düşükler olabilir (10). Faktör XIII eksikliği 3 grupta toplanabilir. Tip I de her iki subunit eksiktir, tip II de subunit A yoktur, tip III de ise subunit B eksiktir. En sık görülen şekli subunit A proteini eksikliğidir $(9,11)$. Faktör XIII yarı ömrü uzun (19 gün) olduğu için, replasman tedavisi başarılıdır. 3-4 haftada bir TDP transfüzyonu ile etkili hemostaz sağlanabilir (10). Bizim çalışmamızda 3 hastada Faktör XIII eksikliği mevcuttu. İkisi kız 1'i erkekti. Üç hastanın da ciddi kanamaları vardı. Yaşayan hastalarımızın birisinde sünnet sonrası ciddi kanama, diğerinde ciddi göbek kanaması ile 6 günlükken tanısı konuldu. Bir diğer hastamız ise bisikletten düşme nedeniyle oluşan iliopsoas kanaması ve sonrasında gelişen intrakranial kanama nedeniyle 8 yaşında exitus oldu.

Sonuç olarak; kanama şikâyeti olan ya da olmayan hastalarda nadir faktör eksikliği tanısı ayırıcı tanıda olmalıdır. Bu hastaların erken dönemde tanısı konularak, ciddi kanamaların önlenmesi ve tedavisi önemlidir.

\section{Çıkar Çatışması}

$\mathrm{Bu}$ çalışmada adı geçen araştırıcıların arasında çıkar çatışması yoktur.

\section{KAYNAKLAR}

1. Manisha M, Ghosh K, Shetty S, Nair S, Khare A, Kulkarni B, et al. Spectrum of inherited bleeding disorders from Western India. Haematologia (Budap). 2002; 1: 39-47.

2. Palla R, Peyvandi F, Shapiro AD. Rare bleeding disorders: diagnosis and treatment. Blood. 2015; 125: 2052-61.

3. Peyvandi F, Cattaneo M, Inbal A, De Moerloose P, Spreafico M. Rare bleeding disorders. Haemophilia. 2008: 202-10.

4. Ünivar A, Celkan T, Fışgın T, Belgemen T, Ar CA, Demir M. Nadir Faktör Eksiklikleri Tanı ve Tedavi Kılavuzu 2013.

5. Bladbjerg EM, Gram J, Jespersen J. Plasma concen-trations of blood coagulation factor VII measured byimmunochemical and amidolytic methods. Scand J Clin Lab Invest. 2000; 60: 161-8.

6. Fışgın T, Balkan C, Celkan T, Kılınç Y, Türker M, Timur $\mathrm{C}$, et al. Rare coagulation disorders: a retrospective analysis of 156 patients in Turkey. Turk J Haematol. 2012; 29: 48-54.

7. Shahbazi S, Mahdian R. Factor VII Gene Defects: Review of Functional Studies and Their Clinical Implications. Iran Biomed J 2019; 23: 165-74.

8. Rosen ED, Xu H, Liang Z, Martin JA, Suckow M, Castellino FJ. Generation of genetically-altered mice producing very low levels of coagulation factorVII. Thromb Haemost. 2005; 94: 493-7.

9. Saito M, Asakura H, Yoshida T, Ito K, Okafuji K, Yoshida T, et al. A familial factor XIII subunit B deficiency. Br J Haematol. 1990; 74: 290-4.

10. Krumdieck R1, Shaw DR, Huang ST, Poon MC, Rustagi PK. Hemorrhagic disorder due to an isoniazid-associated acquired factor XIII inhibitor in a patient with Waldenström's macroglobulinemia. Am J Med. 1991; 90: 639-45.

11. Girolami A, Sartori MT, Simioni P. An updated classification of factor XIII defect. Br J Haematol. 1991; 77: 565-6. 